\title{
Lectin binding to formalin-fixed paraffin sections
}

\author{
A LEATHEM, N ATKINS \\ From the Bland-Sutton Institute of Pathology, Middlesex Hospital Medical School, London W1P 7PN
}

SUMMARY Lectins are potentially useful tools in histopathology for the identification of carbohydrates and distinguishing cells according to their type, differentiation or function. Conjugated to fluorescent or enzyme labels, lectins are simple to use on fresh tissue but fixation and processing sequesters glycoconjugates and dissolves out fat-linked sugars. We describe here the use of labelled antibodies to lectins to localise sites of lectin binding and increase sensitivity, combined with trypsin and neuraminidase to reveal sequestered carbohydrates. Absorbing lectins with appropriate sugars establishes the specificity of binding and allows lectins to be used as sensitive and specific reagents.

Lectins are specific carbohydrate-binding proteins of non-immune origin and of increasing value in identification of cell differentiation and function. They bind non-covalently to carbohydrates and are readily purified, mostly from plant tissues (see review by Gold and Balding). ${ }^{1}$

Carbohydrates occur predominantly at the surface of cells and lectins have been used to explore cell membranes and to distinguish malignant (or transformed cells) from normal cells both in suspension ${ }^{23}$ and through changes in the membrane glycoproteins. ${ }^{4}$ For the histopathologist, a sensitive means of localising and identifying glycoconjugates in tissue sections is to use the binding property of lectins conjugated to fluorescein or enzyme labels.

Human histopathological material produces two major problems for lectin binding not encountered in cell suspensions or cryostat sections: fixation may sequester carbohydrates through protein denaturation and processing to wax dissolves out carbohydrates linked to fats (glycolipids). As a result, methods which work on unfixed, unprocessed material may give very different results on paraffin sections or may not be sufficiently sensitive without some modification to the tissues and reagents.

The techniques we describe have been evolved around a study of binding of lectins from peanut, Bandeiraea, concanavalin A, lentil, ricin, Helix pomatia, Lotus, Ulex, soya and pokeweed to formalin-fixed paraffin sections. Previous reports on the staining of paraffin sections have used direct conjugates of lectins ${ }^{5-7}$ which are expensive and, in our hands, unsatisfactory. We wish to describe here how lectins may be used on routine histopathologi-

Accepted for publication 3 February 1983 cal material using antibodies to lectins to increase their application. The three techniques we have used are shown in Figs 1, 2 and 3.

Lectin binding is easy to demonstrate on frozen sections or smears but on paraffin sections the binding is much attenuated. This reduction resulting from denatured protein with carbohydrate sequestration can largely be reversed by proteolytic enzymes, and dramatically increase the intensity of binding with lectins. Additional exposure of lectin reactive groups can be achieved by digestion of terminal sialic acids with sialidase or neuraminidase. Lectins binding to exposed carbohydrates may then be identified by fluorescein or enzyme conjugated antibodies. As the simple sugar specificity is usually known, the binding of lectins can be blocked and the specificity of staining demonstrated.

By combining these techniques, lectins can be used as highly sensitive and specific reagents to demonstrate differences in cell populations, functions and differentiation using paraffin sections.

\section{Material and methods}

\section{LECTINS}

The lectins were either purchased or were prepared by ourselves using methods to be published elsewhere. Both native and conjugated lectins (to fluorescein and to peroxidase) were diluted in Trisbuffered saline (0.05 M Tris, $0.15 \mathrm{M} \mathrm{NaCl}, \mathrm{pH} \mathrm{7.6)}$ and stored in aliquots of $1 \mathrm{mg} / \mathrm{ml}$ at $-20^{\circ} \mathrm{C}$.

\section{ANTIBODIES TO LECTINS}

Antibodies were raised in rabbits by injection of lectin denatured by heat $\left(60^{\circ} \mathrm{C}\right)$ in the presence of excess $(0 \cdot 1 \mathrm{M})$ specific sugar. The $\mathrm{IgG}$ fraction was 

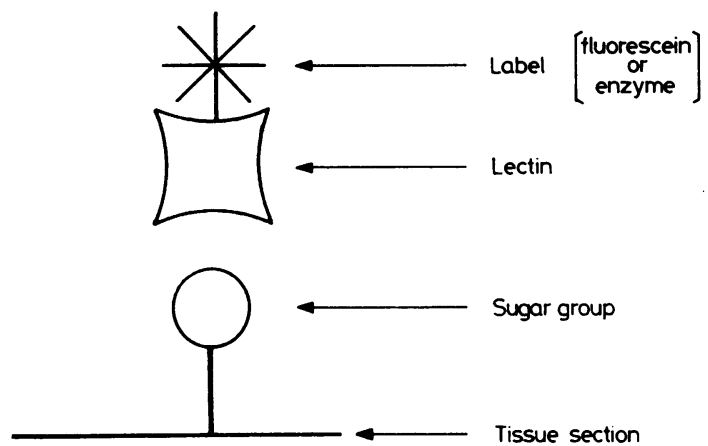

Fig. 1 Direct lectin-conjugate
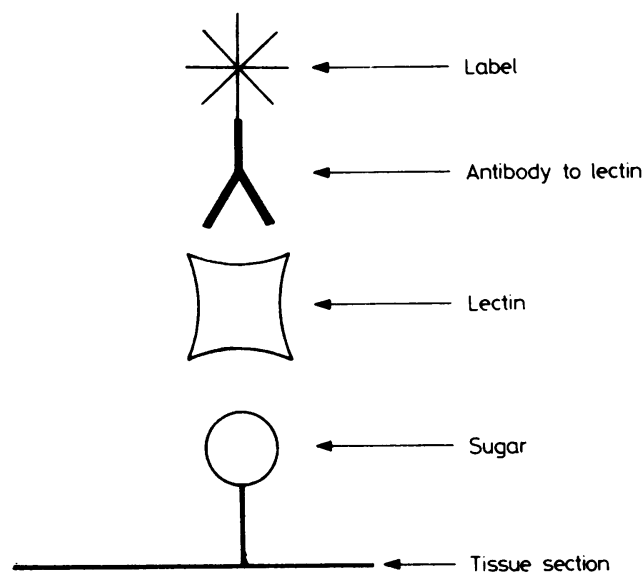

Fig. 2 Direct antibody-lectin
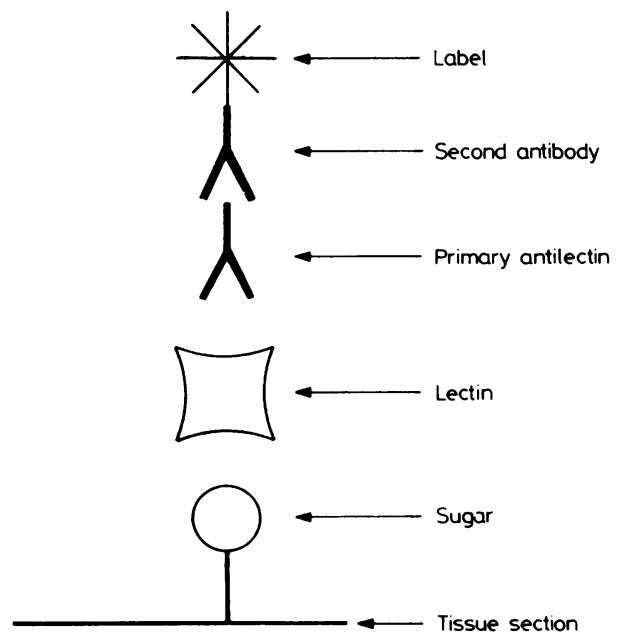

Fig. 3 Indirect antibody-lectin isolated by a protein A-Sepharose 4B column (Pharmacia) either for use in an indirect antibody staining method, or after conjugation to peroxidase ${ }^{8}$ were used in a direct antibody staining method.

Optimal dilutions of lectins and of antisera were determined using a chess-board titration, diluting in Tris-buffered saline, on paraffin sections of mixed human tissues. We found:

(a) The optimum concentration for direct lectin binding (see Fig. 1) to be in the order of 200 (range $50-600) \mu \mathrm{g}$ of conjugated lectin/ml of Tris-buffered saline with $30 \mathrm{~min}$ incubation at room temperature. (b) The optimum concentration for direct antibody lectin (see Fig. 2) and indirect antibody-lectin (see Fig. 3) binding to be native lectin diluted to 10 (range 1-20) $\mu \mathrm{g} / \mathrm{ml}$ of Tris-buffered saline with an incubation of $30 \mathrm{~min}$ at room temperature.

Commercial and home-made antisera to lectins work well in the range of $1 / 50-1 / 100$, diluted in Tris-buffered saline, or using the IgG fraction at 10 $\mu \mathrm{g} \mathrm{IgG/ml}$ Tris-buffered saline.

Peroxidase conjugated swine anti-rabbit Ig from Dakopatts (Mercia-Brocades) was used in indirect antibody method diluted to $1 / 50$ for $30 \mathrm{~min}$. Hydrogen peroxide was used as substrate and aminoethyl carbazole as capture reagent. Alkaline phosphatase conjugated antibody to rabbit IgG was obtained from Sigma and used at $1 / 50$ for $30 \mathrm{~min}$. Naphthol AS-TR phosphate was used as substrate and Fast Red TR as capture reagent. (Reagents obtained from Sigma).

Trypsin grade II was obtained from Sigma and neuraminidase from Hoechst.

Specific soluble sugars were obtained from BDH and Sigma and were stored dessicated at $-20^{\circ} \mathrm{C}$ until used. Lectins were diluted in $0.2 \mathrm{M}$ sugar solutions in Tris-buffered saline as controls to compete for binding sites.

Trypsin solution

Preheat $100 \mathrm{ml}$ distilled water to $37^{\circ} \mathrm{C}$, dissolve 100 $\mathrm{mg}$ of $\mathrm{CaCl}_{2}$ and $100 \mathrm{mg}$ of trypsin (Sigma Grade II), correct to pH 7.0 with $0.1 \mathrm{M} \mathrm{NaOH}$. Filter. Use at $37^{\circ} \mathrm{C}$. Pre-determine optimal incubation time (range 5-60 min) for each new batch of trypsin.

\section{Neuraminidase solution}

Pre-heat $10 \mathrm{ml}$ of sodium acetate buffer -pH 5.5, $0.05 \mathrm{M}$ to $37^{\circ} \mathrm{C}$, dissolve 1 unit of neuraminidase (Hoechst, Sigma, BDH, Calbiochem, Worthington) and $100 \mu \mathrm{l}$ of $1 \% \mathrm{CaCl}_{2}$. Use at once. Predetermine incubation time for each new batch (range 5-60 min).

Peroxidase substrate Aminoethyl carbazole Dissolve $20 \mathrm{mg}$ of 3-amino-9-ethyl carbazole 
(Sigma No A 5754) in $1 \mathrm{ml}$ of dimethylformamide and make up to $100 \mathrm{ml}$ with acetate buffer $\mathrm{pH} 5.0$, $0.05 \mathrm{M}$ and $500 \mu \mathrm{l}$ of $20 \mathrm{vol}$ hydrogen peroxide. Incubate at room temperature for $15-20 \mathrm{~min}$.

\section{Alkaline phosphatase substrate (azo method)}

Twenty milligrams of Naphthol AS-TR, sodium phosphate is dissolved in $100 \mu$ l of dimethylformamide, made up to $100 \mathrm{ml}$ with Tris buffer $\mathrm{pH} \mathrm{9.0,}$ $0.05 \mathrm{M}$ and $40 \mathrm{mg}$ of Fast Red TR added. Filter and use at once. Slides incubated at room temperature for $10 \mathrm{~min}$.

\section{CONTROLS FOR LECTINS}

\section{Positive controls}

The majority of lectins bind to erythrocytes in tissue sections, to the endothelium of blood vessels and to kidney epithelium, thus kidney provides an excellent positive control.

\section{Negative controls}

With few exceptions, the simple sugar specificity for each lectin is known and can specifically inhibit or compete with lectin binding site in tissues.

However, lectins bind more tightly to complex than to simple sugars and exhibit preferential binding. Thus a simple sugar may not easily displace a lectin already bound to a large molecule incorporating a combination of sugars, and displacement of lectins bound to sections by washing in simple sugar solutions may be ineffectual. To overcome this, we attempt to prevent lectin binding to tissues by diluting the lectin in specific (and also in non-specific) sugar solution, $0.2 \mathrm{M}$ in Tris-buffered saline for 60 min prior to using the lectin to stain a section.

If lectin binding is specific, it should be inhibited by the presence of specific sugar but not by nonspecific.

\section{STAINING METHODS}

(a) Direct conjugated lectin (Fig. 1)

Principle: the lectin, conjugated to fluorescein or to peroxidase, is incubated on the section and after washing the fluorescein or peroxidase is visualised.

1 Sections dewaxed and hydrated.

2 Incubate with lectin-conjugate (predetermined concentration, eg range $50-600 \mu \mathrm{g} / \mathrm{ml}$ of Trisbuffered saline) for $30 \mathrm{~min}$ at room temperature.

3 Wash in Tris-buffered saline, three changes of two minutes each.

4 If enzyme-lectin conjugate used, incubate in substrate, counterstain and mount; if fluoresceinlectin conjugate used, mount and examine under fluorescence microscope as soon as possible. (b) Direct antibody method (Fig. 2)

Principle: after incubating native or unconjugated lectin on the section, bound lectin is localised using antibody to lectin, (conjugated to fluorescein, alkaline phosphatase or to peroxidase).

1 Sections dewaxed and hydrated.

2 Incubate with lectin (eg $10 \mu \mathrm{g} / \mathrm{ml}$ Tris-buffered saline, or predetermined dilution) for $30 \mathrm{~min}$ at room temperature.

3 Wash in Tris-buffered saline, three changes of two minutes each.

4 Incubate with conjugated antibody to lectin, diluted $1 / 50$, for $30 \mathrm{~min}$ at room temperature.

5 Wash in Tris-buffered saline, three changes of two minutes each.

6 If enzyme-conjugated used, incubate in substrate, counterstain and mount; if fluoresceinconjugate used, mount and examine as soon as possible.

(c) Indirect antibody method (Fig. 3)

Principle: lectin is incubated on the section and localised by an indirect antibody method.

1 Sections dewaxed and hydrated.

2 Incubate with lectin (eg $10 \mu \mathrm{g} / \mathrm{ml}$ Tris-buffered saline, or predetermined dilution) for $30 \mathrm{~min}$ at room temperature.

3 Wash in Tris-buffered saline, three changes of two minutes each.

4 Incubate with rabbit antilectin serum (1/100 in Tris-buffered saline, or for IgG fraction, $10 \mu \mathrm{g} / \mathrm{ml}$ Tris-buffered saline) for $\mathbf{3 0} \mathrm{min}$ at room temperature.

5 Wash in Tris-buffered saline, three changes of two minutes each.

6 Incubate with fluorescein (Dako), peroxidase (Dako) or alkaline phosphatase (Sigma) conjugated antiserum to rabbit IgG diluted $1 / 50$ for $30 \mathrm{~min}$.

7 Wash in Tris-buffered saline, three changes of two minutes each.

8 If enzyme-antibody conjugate used, incubate in substrate, counterstain and mount; if fluoresceinantibody used, mount and examine under fluorescence microscope as soon as possible.

\section{Results}

(a) Direct conjugated lectin is the most convenient method but to achieve adequate binding we found high concentrations of lectin-conjugate were required, which makes this method almost unacceptably expensive. We have frequently needed such concentrations as peanut $100 \mu \mathrm{g} / \mathrm{ml}$, Helix 100 $\mu \mathrm{g} / \mathrm{ml}$, concanavalin A $500 \mu \mathrm{g} / \mathrm{ml}$ and pokeweed 50 $\mu \mathrm{g} / \mathrm{ml}$ of fluorescein-conjugated lectin. Several commercial batches of peroxidase-conjugated lec- 
tins have failed to produce any staining of tissues and peroxidase-lectin conjugates have consistently required higher concentrations than FITC.

After trypsin and/or neuraminidase treatment, the binding intensity is considerably increased, allowing lower concentrations of lectin to be used. However, with each of these enzymes we find the binding pattern has been altered.

(b) Direct antibody staining produced excellent results with high specificity and high intensity of binding. The optimum concentration for most lectins we have used has been $10 \mu \mathrm{g} / \mathrm{ml}$, using 30minute incubations at room temperature. The optimum antibody titre for these has varied with the source, but in general a $1 / 50$ dilution of both fluorescein and peroxidase conjugated antibody has been satisfactory.

(c) The indirect antibody method has produced the best results in our hands. Using an ELISA technique to determine lectin binding to solid phases, (Leathem and Atkins submitted) we find the direct antibody method to be eight times more sensitive than the direct lectin-conjugate, and the Indirect Antibody method to be $10-20$ times more sensitive than the direct lectin-conjugate.

\section{Discussion}

All lectins we have examined have shown binding to a wide variety of human cells. For cryostat sections the direct lectin conjugate is satisfactory, particularly if the sections are simply air dried, neuraminidase increases the intensity of staining and reveals further binding sites.

But for paraffin sections the high cost of using lectin-conjugates at $100-500 \mu \mathrm{g} / \mathrm{ml}$ limits their use as routine tools, although the lectin-conjugates can be saved and reused. ${ }^{\circ}$ Trypsin and neuraminidase increase the intensity of staining but reveal "new" lectin binding sites (by cleaving off protein-linked carbohydrates and removing terminal sialic acids) and the interpretation of such binding requires considerably more work.

The disappointing direct lectin staining results in our hands with fluorescein and more especially with peroxidase conjugated lectins seem to result partly from a failure of the conjugated lectins to bind (presumably the lectin binding-sites are blocked by conjugate) and partly from low activity of the label.

Many lectins require the presence of metal ions for the binding site to function, and buffer salts (-for example, phosphate) may precipitate these ions. For this reason we use Tris-buffered saline and we find the addition of a cocktail of calcium, magnesium and manganese chlorides to lectin diluting buffer (to give $0.001 \mathrm{M}$ each in Tris-buffered saline) improves the binding of several lectins.

Native or unconjugated lectins, with rare excep-을 tions, are stable proteins and we have stored those $\overrightarrow{\vec{F}}$ mentioned at $4^{\circ} \mathrm{C}$ in dilute solution for 6-12 months without loss of activity. The stability of antisera to등 lectins is even greater and we have stored working $\frac{\bar{c}}{\bar{c}}$ dilutions of antisera for up to 18 months without $\bar{\sigma}_{\bar{\sigma}}$ detectable diminution in staining. Such stability of the lectins and antisera at high dilution has allowedw us to use automated staining for large batches of $\vec{\circ}$ slides.

Peroxidase is a glycoprotein and methods for blocking endogenous tissue peroxidases damage the carbohydrate component; consequently most block-? ing procedures, in particular by sodium borohyd- $\omega$ ride, damage tissue glycoconjugates and reduce lec-. tin binding. Where possible we avoid blocking tissue $A$ enzymes and if necessary either use hydrogen perox- -0

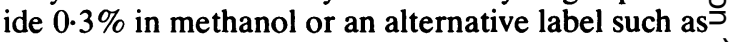
alkaline phosphatase or fluorescein.

The stability of unconjugated lectins together with the high dilutions and consequent economy achieved renders the Antibody-Lectin approach $\mathbb{\infty}_{\infty}$ vastly superior to Direct Lectin staining.

We are most grateful to Jennifer Gardner and Gail Watts for their assistance and to Professor N Woolfo for his encouragement and support of our work.

\section{References}

' Gold ER, Balding P. Receptor-specific proteins. Amsterdam: Excerpta Medica, 1975.

${ }^{2}$ Voyles BA, Kirkland WL, Furmanski P, McGrath CM. Concanavalin A-mediated hemadsorption by normal and malig nant human mammary epithelial cells. Cancer Res 1978;38:1578-83.

${ }^{3}$ Asch BB, Medina D. Concanavalin A-induced agglutinability of normal, preneoplastic and neoplastic mouse mammary cells. $J$ 음 Natl Cancer Inst 1978;61:1423-30.

4 Bramwell ME, Harris H. An abnormal membrane glycoproteino associated with malignancy in a wide range of different tissues. Proc R Soc Lond [Biol] 1978;201:87-106.

stoward PJ, Spicer SS, Miller RL. Histochemical reactivity of peanut lectin-horseradish peroxidase conjugates. $J$ Histochem $\mathbb{O}$ Cytochem 1980;28:979-90.

- West KP, Platts HA, Fletcher A, Walker F. Tissue carbohydrate identification by the use of lectins. J Clin Pathol 1982;35:239-40.

' Walker RA. Mucoid carcinomas of the breast: a study using mucin histochemistry and peanut lectin. Histopathology@ 1982;16:571-80.

${ }^{8}$ Hudson L, Hay FC. Practical Immunology. Oxford: Blackwells Scientific Publications, 1980:237-8.

Requests for reprints to: Dr A Leathem, Bland-Sutton Institute of Pathology, Middlesex Hospital Medical School, London W1P 7PN, England. 